\title{
In vitro growth of Ganoderma boninense isolates on novel palm extract medium and virulence on oil palm (Elaeis guineensis) seedlings
}

\author{
Siang Ming Kok ${ }^{1}$, Yit Kheng Goh ${ }^{1 *}$, Hun Jiat Tung ${ }^{2}$, Kah Joo Goh ${ }^{1}$, Wei Chee Wong ${ }^{2}$ and You Keng Goh ${ }^{1}$ \\ ${ }^{1}$ Advanced Agriecological Research Sdn. Bhd., No. 11 Jalan Teknologi 3/6, Taman Sains Selangor 1, Kota Damansara, \\ 47810 Petaling Jaya, Selangor Darul Ehsan, Malaysia. \\ ${ }^{2}$ Applied Agricultural Resources Sdn Bhd (AAR) - University of Nottingham Malaysia Campus (UNMC) Biotechnology \\ Research Centre, Jalan Broga 43500 Semenyih, Selangor, Malaysia. \\ E.mail: gohykheng@aarsb.com.my
}

Received 10 July 2012; Received in revised form 9 August 2012; Accepted 9 August 2012

\begin{abstract}
Aims: Basal stem rot (BSR) disease caused by Ganoderma pathogenic fungi, especially Ganoderma boninense is thriving rapidly in both areas with coastal and inland soils. The objectives of this study were to isolate and characterize Ganoderma isolates collected from various locations in Peninsular Malaysia through the comparison of their growth rate in vitroly on conventional and novel palm extract media, and to determine the degree of virulence caused by the isolates in oil palm seedlings.

Methodology and results: In this study, 12 Ganoderma isolates were collected from infected oil palm trees, from various locations - Johor, Negeri Sembilan, Kedah, Perak, Pahang, and Kelantan, in Malaysia in year 2011. Twelve Ganoderma isolates were identified using molecular method with primer set that targeted at small-subunit 18S rDNA fragment, and characterized by determining the in vitro growth rate, and degree of virulence in 2-month-old oil palm seedlings in the nursery using both disease incidence (DI) and disease severity index (DSI) as the measurements to quantify the infection. All the Ganoderma isolates were identified as G. boninense and sequences of the respective isolates were deposited in GenBank. In general, all the isolates proliferated faster on oil palm extract medium (OPEM) compared to malt extract agar (MEA). Twelve $G$. boninense isolates were observed to illustrate different degree of virulence ranging from highly pathogenic to least pathogenic.

Conclusion, significance and impact of study: Cultures of $12 \mathrm{G}$. boninense isolates were observed to show faster growth rate $(P<0.014)$ on OPEM under in vitro conditions compared to conventional MEA medium, except Bt Lintang G10 and GBA G12 isolates. OPEM medium could provide a better alternative for maintaining and culturing Ganoderma strains. In the current study, both DI and DSI were highly correlated. However, there were low linear relationships $\left(R^{2}<\right.$ 0.423 ) between mycelia growth rate (on MEA and OPEM) and degree of virulence (DI and DSI) at 12-, 14- and 16weeks after treatments among the $G$. boninense isolates tested. Furthermore, different degrees of virulence in twelve separate Ganoderma isolates were reported. Therefore, it is crucial to incorporate more than one isolate into any researches on screening for Ganoderma resistance or tolerance planting materials, searching for potential biological control agents, and studying bitrophic or tri-trophic interactions. In addition, this study was aimed to isolate $G$. boninense strains with various virulence levels for future studies.
\end{abstract}

Keywords: Ganoderma, in vitro growth, molecular analysis, virulence

\section{INTRODUCTION}

The oil palm industry in Indonesia and Malaysia, the two largest palm oil producers, is being threatened by the basal stem rot (BSR) disease, which was reportedly caused by Ganoderma boninense. The disease incidences are anticipated to escalate with continuous introduction of monoculture oil palm planting materials (Cooper et al., 2011 and Turner, 1981). More oil palm cultivation regions around the world are reporting similar disease, although it is unclear whether they pertain to the same fungal disease (Kinge and Mih, 2011). Yield losses due to BSR disease in mature plantings were found to be relatively more severe in Malaysia and Indonesia compared to Africa, Papua New Guinea and Thailand (Idris et al., 2004), where palms as young as 1-2 years were reported to be infected after planting ( $\mathrm{Ho}$ and Nawawi, 1985 and Singh, 1991). Diseased palms often show few external symptoms during early infection stages. Severely infected palms may exhibit fracture of frond petioles, multiple unopened spear leaves unrelated to dry weather conditions, decay of the bole, and having 
Ganoderma boninense fruiting bodies on the root, stem, or bole regions (Cooper et al., 2011). Once the disease has affected more than $10 \%$ of the stand, economic losses will begin to manifest (Hasan and Turner, 1998). With the loss of $50 \%$ stand on average, a reduction of $35 \%$ in fresh fruit bunch (FFB) had been reported (Subagio and Foster, 2003).

Various methods to artificially inoculate oil palm seedlings had been carried out. Lim et al., (1992) successfully inoculated injured roots of healthy 15-monthold palms by placing wheat-oat medium inoculated with Ganoderma. Idris et al., (2004) employed root inoculation method where primary roots of oil palm seedlings in polybag were exposed and inserted into test tubes containing various Ganoderma spp. isolates grown in POPW medium (mixture of paddy, oil palm wood sawdust, supplemented with sucrose, ammonium sulphate, calcium sulphate, and bacto peptone). Khairudin et al., (1991) reported $100 \%$ success in infecting oil palm by wrapping bare roots of seedlings over rubber wood blocks (RWB) $(6 \times 6 \times 12 \mathrm{~cm}$ or 432 $\mathrm{cm}^{3}$ ) pre-inoculated with Ganoderma boninense. In Indonesia, inoculating seedlings using oil palm and rubber wood blocks in a range of sizes (Rees et al., 2007) as the substrates had been reported. However, Ganodermainoculated RWB still remains the most effective option for artificial inoculation of Ganoderma spp. to screen for Ganoderma tolerance and to study various control measures in the nursery (Breton et al., 2006 and Nur Ain Izzati and Abdullah, 2008). Common RWB sizes used to inoculate with Ganoderma fungal mycelia and recorded to be effective in infecting oil palm seedlings were $3 \times 3 \times 3$, $6 \times 6 \times 6,6 \times 3 \times 3,5 \times 5 \times 15$ and $6 \times 6 \times 12 \mathrm{~cm}^{3}$ (Rees et al., 2007 and Sariah et al., 1994).

Ganoderma boninense isolates selected for artificial inoculation were suggested to be one of the main parameters affecting the level of disease severity in the tested oil palm seedlings (Breton et al., 2006). Breton et al., (2006) also found that there were variations in the level of aggressiveness in seven isolates collected from three different estates in Indonesia. Information related to different level of virulence among $G$. boninense isolates collected from various locations in Peninsular Malaysia will be useful for future researches. Therefore, the objectives of this study were to investigate growth rates of different $G$. boninense isolates under in-vitro conditions and variations in the degree of virulence in oil palm seedlings caused by these Ganoderma isolates. Furthermore, preliminary study into the growth of $G$. boninense on medium with oil palm derivative is vital for understanding the physiology of this fungal pathogen.

\section{MATERIALS AND METHODS}

\section{Fungal isolates and culture conditions}

Twelve different Ganoderma isolates used in this study were obtained from the basidiocarps produced at the stem base of infected oil palms. Each isolate was obtained from 12 different sites in 7 states in Peninsular Malaysia (Table
1). Isolation of Ganoderma tissues from the fresh basidiocarps was performed by using Ganodermaselective medium (GSM) (Ariffin et al., 2000 and Ariffin and Seman, 1991). Procedures and components required for preparing the Ganoderma-selective medium was outlined by Ariffin and Seman (1991) and Rees et al., (2007). After isolation of Ganoderma mycelia, pure cultures were maintained on malt extract agar (MEA) (Difco) in petri dishes prior to in-vitro growth, DNA extraction and inoculum preparations.

Table 1: Isolates of Ganoderma boninense collected from oil palms infected with basal stem rot disease were used in this study with GenBank accession number (18S smallsubunit ribosomal RNA gene).

\begin{tabular}{lll}
\hline Isolate/Estate & Location/State & $\begin{array}{l}\text { Accession } \\
\text { Number }\end{array}$ \\
\hline Paloh G14 & Johor & JQ665238 \\
Fraser G8 & Johor & JQ665233 \\
Ulu Pedas G6 & Negeri Sembilan & JQ665231 \\
GBA G12 & Kedah & JQ665237 \\
Jeram G5 & Selangor & JQ665230 \\
Pinji G1 & Perak & JQ665226 \\
Pelam G11 & Kedah & JQ665236 \\
Bt Lintang G10 & Kedah & JQ665235 \\
Bebar G4 & Pahang & JQ665229 \\
Sg. Jernih G3 & Pahang & JQ665228 \\
Sg. Sokor G9 & Kelantan & JQ665234 \\
Pasir Gajah G2 & Kelantan & JQ665227 \\
\hline
\end{tabular}

In-vitro growth studies for all twelve Ganoderma isolates were carried out by using two different types of media - conventional MEA (Difco) and OPEM (oil palm extract medium). OPEM was prepared as follows: $150 \mathrm{~g}$ of oil palm trunk sawdust obtained from healthy palms were mixed well in $200 \mathrm{~mL}$ sterilized distilled water. Oil palm extract was obtained by squeezing the mixture through several layers of cheesecloth. The extract was reconstituted to $1 \mathrm{~L}$ by adding sufficient distillated $\mathrm{H}_{2} \mathrm{O}$ and the mixture was stirred and agitated for $30 \mathrm{~min}$. Debris was removed from oil palm extract by filtering through filter paper (Whatman Grade No. 1) and the filtrate (approximately $900 \mathrm{~mL}$ ) was added with $16.8 \mathrm{~g}$ of MEA. The OPEM was autoclaved at $121{ }^{\circ} \mathrm{C}$ for $20 \mathrm{~min}$.

Ten $\mathrm{mm}$ diameter mycelial plugs of the Ganoderma isolates were taken from the actively growing 5-day-old cultures and placed in the centre of the MEA and OPEM plates in 5 replicates. Linear mycelial growth of all 12 Ganoderma isolates on MEA and OPEM were measured and recorded daily for 7 days. Radius measurements (in $\mathrm{mm}$ ) were recorded for respective Ganoderma isolates from center of the mycelial plug to the edge of the fungal colony. Average growth rate for individual Ganoderma isolates was obtained by dividing total of daily radial mycelial growth readings for a week by seven. 


\section{Molecular analysis of Ganoderma isolates}

All the Ganoderma isolates outlined in Table 1 were cultured on solid MEA medium amended with antibiotics $(100 \mathrm{mg} / \mathrm{L}$ streptomycin sulphate and $12 \mathrm{mg} / \mathrm{L}$ kanamycin sulphate) (Sigma-Aldrich) at room temperature $\left(26 \pm 2^{\circ} \mathrm{C}\right)$ for 5 days prior to DNA extraction. Genomic DNA was extracted with the FastDNA Spin Kit (MP Biomedicals, USA) as per manual instruction. Primer set SSU-817-5' (5 TTA GCA TGG AAT AAT RRA ATA GGA 3') and SSU1536-3' (5' ATT GCA ATG CYC TAT CCC CA 3') (Borneman and Hartin, 2000) which targeted the smallsubunit 18S rDNA fragment were used in the polymerase chain reaction (PCR). The PCR mixtures consisted of 0.2 $\mathrm{mM}$ dNTPs (iNtRON Biotechnology, Korea), $0.4 \mu \mathrm{M}$ of each primer, $0.1 \mathrm{U}$ of Taq DNA Polymerase (iNtRON Biotechnology, Korea), 5 to $10 \mathrm{ng}$ of extracted fungal DNA, $20 \mu \mathrm{g}$ bovine serum albumin (BSA) (Amresco, USA) and $17 \mu \mathrm{L}$ of sterilized ultra-pure Millipore water to make up the $50 \mu \mathrm{l}$ reaction. The thermocycling profile was as follows: $94^{\circ} \mathrm{C}$ for $4 \min (1 \mathrm{cycle}) ; 94^{\circ} \mathrm{C}$ for $20 \mathrm{~s}, 55^{\circ} \mathrm{C}$ for $10 \mathrm{~s}$ and $72{ }^{\circ} \mathrm{C}$ for $1 \mathrm{~min}$ ( 35 cycles); and $72{ }^{\circ} \mathrm{C}$ for $5 \mathrm{~min}$ (1 cycle) in Veriti ${ }^{\mathrm{TM}}$ Thermal Cycler (Applied Biosystem, USA). PCR products were visualized in $1 \% \mathrm{w} / \mathrm{v}$ agarose gel (Vivantis, USA) in $1 \times$ TBE buffer with $10 \times$ SYBR $^{\circledR}$ Safe DNA gel stain (Invitrogen, USA) under $302 \mathrm{~nm}$ UV translumination using Aplhalmager ${ }^{\circledR} \mathrm{HP}$ (Alpha Innotech, USA). Purified PCR products were sent to Macrogen, Korea for sequencing. 18S sequences from the specimen of 12 different Ganoderma isolates were submitted to GenBank under accession numbers as outlined in Table 1.

\section{Oil palm seedlings and preparation}

Germinated oil palm seeds (Dumpy Yangambi Avros DxP) (Seed Production Unit, Applied Agricultural Resources Sdn. Bhd., Malaysia) were used throughout the trial. Germinated seeds were grown in $15 \times 21 \mathrm{~cm}$ black polythene bags in a mixture of $50 \%$ fine and $50 \%$ coarse sandy soils supplemented with Egyptian rock phosphate (ERP) at a rate of $10 \mathrm{~g}$ per bag. The germinated seeds were planted in the nursery with $50 \%$ shade at Sungai Buloh, Selangor, Malaysia for 2 months prior to transplanting into $38 \times 51 \mathrm{~cm}$ black polythene bags and watered twice daily. Foliar liquid NPK fertilizer 14:4:4 at 5L (25 mL concentrated foliar fertilizer in $5 \mathrm{~L}$ ) per 100 seedlings was drenched weekly.

\section{Preparation of rubber wood blocks and artificial inoculation}

Blocks of wood with the defined size of $6 \times 6 \times 12 \mathrm{~cm}$ drilled with $1 \mathrm{~cm}$ diameter holes (as illustrated in Figure $1 \mathrm{~A}$ ) were obtained from the rubber trunks (Hevea brasiliensis). Rubber wood blocks (RWB) were boiled at $100{ }^{\circ} \mathrm{C}$ in pressurized cooker for $3 \mathrm{hrs}$. The blocks were then soaked in Horlicks solution $(125 \mathrm{~g} / \mathrm{L}$ of sterilized distillated $\mathrm{H}_{2} \mathrm{O}$ ) (Horlicks powder: Glaxo Smith Kline, Malaysia) for $18 \mathrm{hrs}$ (Dr. Liew K.W., personal communication). Horlicks-treated blocks were placed in double layers of clear, heat resistant plastic bags after being air-dried for $20 \mathrm{~min}$ and autoclaved at $121.7^{\circ} \mathrm{C}$ for 1 hr. The processed blocks were inoculated with approximately 14 pieces of mycelial plugs at the size of 1 $\mathrm{cm}^{2}$ excised from the actively growing 5-days-old Ganoderma cultures sub-cultured on the OPEM medium for 5 days. Ganoderma-inoculated RWBs were incubated at room temperature $\left(27^{\circ} \mathrm{C}\right)$ in darkness for 8 weeks. These Ganoderma-colonized RWBs were then used as fungal inoculum source for the virulence studies.

\section{Effect of different Ganoderma boninense isolates on oil palm seedlings}

Two-month-old seedlings grown on sandy soils (1:1 fine:coarse sandy soils) with similar uniformity were selected, uprooted carefully and placed over the $G$. boninense-inoculated RWBs, ensuring all the primary roots were in contact with the RWBs. Two types of control were incorporated into this experiment (Table 2). Seedlings were then transferred and grown in $38 \times 51 \mathrm{~cm}$ black polythene bags filled with Bungor series soil (Typic Paleudult) (Paramananthan 2000) taken from the top 45 $\mathrm{cm}$. Control and treated seedlings were watered twice daily and liquid foliar 14/4/4 NPK fertilizer at 5 L per 25 seedlings was drenched at weekly intervals. Cypermethrin and amitraz were used in bi-weekly intervals for controlling leaf eating caterpillars and spider mites.

Presence of potential symptoms or signs due to Ganoderma boninense infection, such as presence of fungal mass or fruiting bodies, yellowing or browning of leaf, and stunted growth, was recorded weekly over a period of 16 weeks. Two separate formulae - disease incidence (DI) and disease severity index (DSI) were incorporated into this study to assess the degree of virulence caused by $G$. boninense isolates. DI was determined based on: $\mathrm{DI}=$ Number of seedlings identified as diseased / number of seedlings per treatment set) $x$ $100 \%$ (Campbell and Madden, 1990). DSI was calculated based on the formula proposed by Sapak et al. (2008), with slight modifications: $\mathrm{DSI}=$ (number of seedlings in the rating $x$ rating number/disease class value)/(total number of seedlings assessed $x$ highest rating or disease class value). For DSI calculation, the seedlings were scored for disease class value based on the signs or symptoms of infection delineated in Table 3 using the scale of 0 to 6 . The signs and symptoms of infection in the respective classes are illustrated in Figure 2. The experiment was set up as a randomized complete block design (RCBD) in which each treatment was replicated ten times (with each individual seedling as one replicate) and each block of replication for all 14 treatments were randomized (Figure 1B). Stem bole and roots of the inoculated seedlings were investigated and Ganoderma infection was confirmed by re-isolation of $G$. boninense at $2 \mathrm{~cm}$ intervals for both the tissues mentioned by plating on GSM (Rees et al., 2007). Prior to plating on GSM, the stem bole and roots were surface-sterilized with $70 \%$ alcohol for $5 \mathrm{~min}$. 
Mal. J. Microbiol. Vol 9(1) 2013, pp. 33-42

Table 2: Disease incidence (DI) and disease severity index (DSI) of oil palm seedlings at 8, 10, 12, 14, and 16 weeks after artificial inoculation for 14 different treatments (with twelve separate Ganoderma boninense isolates and two controls).

\begin{tabular}{|c|c|c|c|c|c|c|c|c|c|c|c|}
\hline & \multirow{2}{*}{$\begin{array}{c}\text { Treatment } \\
\text { (Description) }\end{array}$} & \multicolumn{5}{|c|}{$\begin{array}{l}\text { Disease incidence } \\
\text { (after weeks) }(\%)^{\ddagger}\end{array}$} & \multicolumn{5}{|c|}{ Mean of disease severity index (after weeks) $(\%)^{\dagger \S}$} \\
\hline & & 8 & 10 & 12 & 14 & 16 & 8 & 10 & 12 & 14 & 16 \\
\hline $\mathrm{T} 1$ & Control 1* & 0 & 0 & 0 & 0 & 0 & $0 \mathrm{a}$ & $0 \mathrm{c}$ & $0 \mathrm{~d}$ & $0 \mathrm{~d}$ & $0 \mathrm{e}$ \\
\hline $\mathrm{T} 2$ & Control 2* & 0 & 0 & 0 & 0 & 0 & $0 \mathrm{a}$ & $0 \mathrm{c}$ & $0 d$ & $0 \mathrm{~d}$ & $0 \mathrm{e}$ \\
\hline T3 & Paloh G14 & 10 & 50 & 70 & 90 & 90 & 3.3 (3.3) a & $16.7(6.1) a b$ & $36.7(12.1) \mathrm{a}$ & 63.3 (12.9) a & $85.0(10.1) a b c$ \\
\hline $\mathrm{T} 4$ & Fraser G8 & 0 & 0 & 10 & 10 & 20 & $0 \mathrm{a}$ & $0 \mathrm{c}$ & $3.3(3.3) \mathrm{cd}$ & 3.3 (3.3) cd & $6.7(4.4) \mathrm{e}$ \\
\hline $\mathrm{T} 5$ & Ulu Pedas G6 & 0 & 10 & 40 & 90 & 100 & $0 \mathrm{a}$ & 3.3 (3.3) bc & 16.7 (8.6) abc & $66.7(10.5) \mathrm{a}$ & 90.0 (8.3) ab \\
\hline T6 & GBA G12 & 0 & 20 & 30 & 70 & 90 & $0 \mathrm{a}$ & 10.0 (6.7) abc & $18.3(9.8) a b c$ & $30(11.9) b c$ & $83.3(10.5) a b c$ \\
\hline T7 & Jeram G5 & 0 & 0 & 0 & 20 & 40 & $0 \mathrm{a}$ & $0 \mathrm{c}$ & $0 \mathrm{~d}$ & $6.7(4.4) \mathrm{cd}$ & $26.7(12.2) \mathrm{de}$ \\
\hline $\mathrm{T} 8$ & Pinji G1 & 0 & 0 & 0 & 10 & 50 & $0 \mathrm{a}$ & $0 \mathrm{c}$ & $0 d$ & $8.3(8.3) \mathrm{cd}$ & $35.0(13.0) \mathrm{de}$ \\
\hline T9 & Pelam G11 & 0 & 10 & 20 & 80 & 100 & $0 \mathrm{a}$ & $3.3(3.3) b c$ & $8.3(5.7) \mathrm{cd}$ & 50 (12.4) ab & $85.0(8.4) b c$ \\
\hline T10 & Bt Lintang G10 & 20 & 60 & 70 & 90 & 100 & $6.7(5.1) \mathrm{a}$ & $28.3(9.0) \mathrm{a}$ & $33.3(9.9) \mathrm{a}$ & $71.7(12.2) \mathrm{a}$ & $100 \mathrm{a}$ \\
\hline T11 & Bebar G4 & 0 & 10 & 10 & 40 & 90 & $0 \mathrm{a}$ & $5.0(5.0) b c$ & $8.3(8.3) \mathrm{cd}$ & 31.7 (13.5) bc & $78.3(10.8) b c$ \\
\hline T12 & Sg. Jernih G3 & 20 & 40 & 50 & 70 & 90 & $6.7(4.4) \mathrm{a}$ & 15.0 (6.3) ab & 26.7 (10.6) abc & 45 (14.5) ab & 73.3 (12.7) bc \\
\hline T13 & Sg. Sokor G9 & 0 & 20 & 20 & 50 & 70 & $0 \mathrm{a}$ & $5.0(3.6) b c$ & $5.0(3.6) \mathrm{cd}$ & 30.0 (13.3) bc & $56.7(13.9) \mathrm{cd}$ \\
\hline T14 & Pasir Gajah G2 & 10 & 40 & 60 & 90 & 100 & $1.7(1.7) \mathrm{a}$ & $15.0(7.2) a b$ & 25 (8.3) abc & 56.7 (11.7) a & 88.3 (8.3) ab \\
\hline
\end{tabular}

* Control 1 and 2 represent treatment without rubber wood block (RWB) and with uninoculated RWB, respectively.

${ }^{\ddagger}$ Disease incidence (DI) was determined using this formula:

$\mathrm{DI}=$ (Number of seedlings identified as diseased / number of seedlings per treatment set) $\times 100 \%$

${ }^{\dagger}$ Disease severity index (DSI) was calculated using following formula:

$\mathrm{DSI}=$ (number of seedlings in the rating $\mathrm{x}$ rating number/disease class value)/(total number of seedlings assessed $\mathrm{x}$ highest rating or disease class value) (Sapak et al., 2008).

DSI for respective treatments at $8,10,12,14$ and 16 weeks after artificial inoculation presented in mean of 10 replications numbers in the bracket were standard error. DSI at different weeks after inoculation were analyzed separately. Means within each column of weeks after inoculation followed by the same letter are not significantly different at $P=0.05$ after Kruskal-Wallis test followed Mann-Whitney test. 


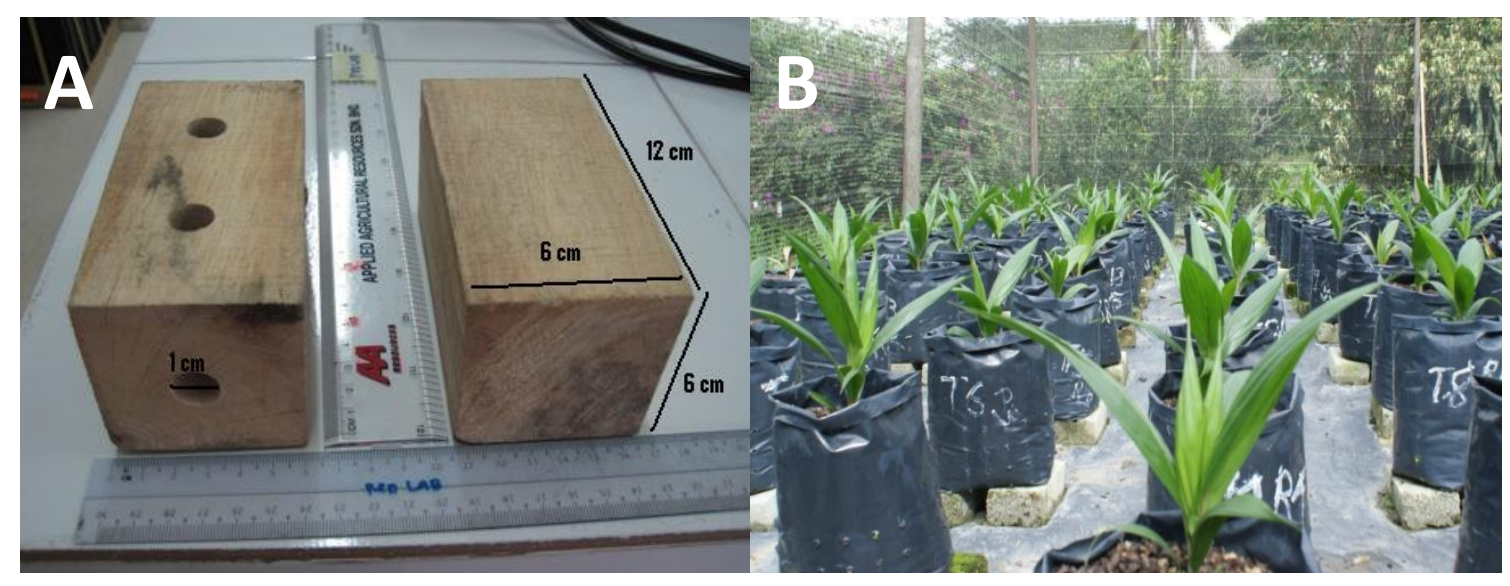

Figure 1: (A) Dimensions for the rubber wood block (RWB) used in this study with drilled block on the left and original block on the right. (B) Oil palm seedlings challenged with Ganoderma boninense.

Table 3: Appearances and symptoms of oil palm seedlings in relations to the respective disease classes used for determination of disease severity index.

\begin{tabular}{ll}
\hline Disease class & Appearances and symptoms of infection \\
\hline 0 & Healthy \\
1 & Without leaf symptoms, fungal mass $>2 \mathrm{~cm}$ away from bole \\
2 & Without leaf symptoms, fungal mass at bole \\
3 & With leaf symptoms, without fungal mass \\
4 & With leaf symptoms, fungal mass $>2 \mathrm{~cm}$ away from bole \\
5 & With leaf symptoms, fungal mass at bole \\
6 & Dead \\
\hline
\end{tabular}

\section{Statistical analyses}

Differences in means for the fungal growth rate $(\mathrm{mm} /$ day) on both MEA and OPEM media among 12 different $G$. boninense isolates used in the in-vitro studies were determined using analysis of variance (ANOVA) and least significant difference (LSD) test at $P=0.05$ (SPSS, 1990). Means for disease severity index (DSI) of oil palm seedlings challenged with the 12 different $G$. boninense isolates and two controls at $8,10,12,14$, and 16 weeks after artificial inoculations were not normally distributed. Therefore, differences in means of DSI among 14 different treatments at different time points were analyzed with the Kruskal-Wallis test and followed by Mann-Whitney $U$ test at $P=0.05$ (SPSS, 1990). Differences in means for the fungal growth rate ( $\mathrm{mm} /$ day) between MEA and OPEM for respective Ganoderma boninense isolates were analyzed separately using T-test at $P=0.05$ (SPSS, 1990).

Linear relationships between fungal growth rates ( $\mathrm{mm} /$ day) (on MEA and OPEM) with the degree of virulence (DI and DSI) at 12-, 14- and 16-weeks after treatments were determined using linear regression approach to obtain the $\mathrm{R}$-squared values respectively (SPSS, 1990). Furthermore, the linear relationships between DI and DSI at four separate time points - 10-, 12-, 14-, and 16-weeks after treatments were estimated using linear regression approach as well for obtaining the R-squared values.

\section{RESULTS AND DISCUSSION}

\section{Molecular characterization of Ganoderma isolates}

Determination of Ganoderma isolates using molecular approaches was proposed by Bridge et al., (2000) for Ganoderma cultures originated from environmental samples. Therefore, molecular analysis with SSU-817 and SSU-1536 primer set to target at the $18 \mathrm{~S}$ small sub-unit rDNA region was conducted on the 12 Ganoderma isolates listed in Table 1. All the isolates sequenced were having the 18S rDNA sequences with the size ranging from 735-745 base pairs. Sequencing results showed that 11 out of 12 isolates had approximately $98-100 \%$ similarity to the Ganoderma boninense FA-PP28 isolate (isolated from Malaysia - Moncalvo and Buchanan 2008) submitted to GenBank under the accession number of AF255198. The exception was obtained from Jeram, Selangor, which had $92 \%$ similarity to $G$. boninense FA-PP28. The $18 S$ rDNA sequences obtained from this study were submitted to GenBank with accession numbers as listed in Table 1. The four most common Ganoderma species isolated from infected oil palms reported in Malaysian oil palm 
plantations are $G$. boninense, $G$. zonatum, $G$. miniatocinctum and $G$. tornatum with $G$. boninense being the most pathogenic and $G$. tornatum being nonpathogenic and saprophytic (Idris, 1999 and Miller, 1995). In addition, Ganoderma zonatum and G. miniatocinctum were less pathogenic toward oil palms (Idris, 1999 and Pilotti, 2005). Based on the comparisons between sequences obtained from the 12 Ganoderma isolates used in this study and sequence of $G$. boninense FAPP28 from GenBank, the results demonstrated that all twelve isolates were Ganoderma boninense and not the other three Ganoderma species ( $G$. zonatum, $G$. miniatocinctum and G. tornatum).

\section{In-vitro growth rate for Ganoderma boninense isolates}

Linear mycelial growths for all twelve Ganoderma boninense isolates cultured from dikaryotic tissues of basidiocarps obtained from various locations in Peninsular Malaysia (Table 1) were studied under in vitro conditions. Two growth media - MEA and OPEM were used in this experiment to evaluate the linear mycelial growth rate for these $G$. boninense isolates. The fungal mycelial growth rates for all the isolates tested were significantly faster on OPEM compared to MEA $(P<0.014$, with T-test at $P=$ 0.05) (Table 3, except for Bt. Lintang G10 and GBA G12 isolates. This was in concordance to the positive effects posed by host plant extracts on mycotoxin production and growth rate of pathogenic Alternaria helianthi (Robeson and Strobel, 1986). Spore germination in basidiomycetous Crinipellis perniciosa was also induced by the extracts obtained from cocoa host plants (Evans and Bastos, 1980). Furthermore, germination of Ganoderma basidiospores and mycelial growth were better in media with natural ingredients such as Lima bean compared with conventional synthetic media (Ho and Nawawi, 1986a and Ho and Nawawi, 1986b).

Growth rate of Paloh and Ulu Pedas G. boninense isolates on MEA medium was significantly faster compared to isolates from Pinji, Bt. Lintang and Bebar. On the other hand, G. boninense isolates from Paloh, Ulu Pedas, Sg. Sokor, and Pasir Gajah were observed to show significantly better growth on OPEM compared to isolates from GBA and Bt. Lintang. Growth rates for the 12 isolates varied when grown on MEA and OPEM (Table 4). Differences in growth rates for the $G$. boninense isolates were reported in this study. Variations in the correlations between in-vitro growth rate and fungal virulence or aggressiveness were observed, as degree of virulence in few pathogenic fungi tended to be positively correlated with the growth rate and some showed negative correlations (Brasier and Webber, 1987, Brennan et al., 2003, Irzykowska and Bocianowski, 2008). Therefore, we were interested in investigating the correlation between in vitro growth and virulence in oil palm seedlings. Growth rate of Paloh and Ulu Pedas $G$. boninense isolates on MEA medium,was significantly faster compared to isolates from Pinji, Bt. Lintang and Bebar. On the other hand, G. boninense isolates from Paloh, Ulu Pedas, Sg. Sokor, and
Pasir Gajah were observed to show significantly better growth on OPEM compared to isolates from GBA and Bt. Lintang. Growth rates for the 12 isolates varied when grown on MEA and OPEM (Table 4). Differences in growth rates for the $G$. boninense isolates were reported in this study. Variations in the correlations between in-vitro growth rate and fungal virulence or aggressiveness were observed, as degree of virulence in few pathogenic fungi tended to be positively correlated with the growth rate and some showed negative correlations (Brasier and Webber, 1987, Brennan et al., 2003, Irzykowska and Bocianowski, 2008). Therefore, we were interested in investigating the correlation between in vitro growth and virulence in oil palm seedlings.

\section{Effect of different Ganoderma boninense isolates on oil palm seedlings}

Fungal white mass was observed at the bole of the oil palm seedlings without any leaf symptoms (Disease class 2) (Table 3, Figure 2C) for the treatments of Paloh (T3), Bt Lintang (T10), Sg. Jernih (T12) and Pasir Gajah (T14) approximately 8 weeks after inoculation. On the other hand, the treatments with Jeram (T7) and Pinji (T8) isolates had fungal mass starting to form at the bole only by the 14 weeks after inoculation. By 16 weeks after inoculation, four out of the 12 isolates (Ulu Pedas/T5, Pelam/T9, Bt Lintang/T10 and Pasir Gajah/T14) caused $100 \%$ disease incidence (DI) while isolates obtained from Fraser (T4), Jeram (T7) and Pinji (T8) were only causing $20-50 \%$ DI (Table 2). At the end of the experiment (16 weeks after inoculation), only treatment T10 (Bt Lintang) was noted to have $100 \%$ casualties for all the seedlings tested. However, there was no dead seedling detected for isolate from Fraser (T4). Ganoderma boninense was reisolated on GSM from all the seedlings inoculated or treated with Ganoderma rubber wood inoculum. The $G$. boninense was found in both roots and stem bole for the treated seedlings (Data not shown). Furthermore, pseudosclerotial-like structures were noted covering the roots. These structures were also reported as survival organs for Ganoderma by Rees et al., (2009). Most of the literatures reported that the signs or symptoms for diseased seedlings only manifested approximately 3-4 months after treatments for 4 to 6-month-old seedlings (Breton et al., 2006, Nur Ain Izzati and Abdullah, 2008, Rees et al., 2007, Sariah et al., 1994). However, in this study, the appearance of fungal mass or initial infection symptom was noted as early as 2 months after inoculation. This may be due to the result of the younger age of the seedlings used in this experiment (2 months old). In addition, this also could be due to different seedling or planting materials incorporated in the study. Different planting materials were proposed to have different levels or degrees of disease tolerance or susceptibility, lignin content and mechanisms to counter the Ganoderma infection (Breton et al., 2006, Cooper et al., 2011, Idris et al., 2004, Paterson, 2007). 
Table 4 Growth rate (mm/day) for 12 different Ganoderma boninense isolates on Malt extract agar (MEA) and oil palm extract medium (OPEM).

\begin{tabular}{lll}
\hline Isolate & \multicolumn{2}{c}{ Growth rate $\left(\mathrm{mm} /\right.$ day $^{\ddagger}{ }^{\ddagger}$} \\
\cline { 2 - 3 } MEA $^{\ddagger}$ & OPEM $^{\ddagger}$ \\
\hline Paloh G14 & $3.80(0.06) \mathrm{b}$ & $5.07(0.13) \mathrm{a}$ \\
Fraser G8 & $3.11(0.16) \mathrm{de}$ & $3.99(0.18) \mathrm{d}$ \\
Ulu Pedas G6 & $4.43(0.18) \mathrm{a}$ & $5.13(0.19) \mathrm{a}$ \\
GBA G12 & $3.30(0.16) \mathrm{cd}$ & $2.99(0.40) \mathrm{f}$ \\
Jeram G5 & $3.10(0.18) \mathrm{de}$ & $4.36(0.24) \mathrm{bc}$ \\
Pinji G1 & $2.97(0.08) \mathrm{e}$ & $3.91(0.51) \mathrm{d}$ \\
Pelam G11 & $3.30(0.18) \mathrm{cd}$ & $4.11(0.11) \mathrm{cd}$ \\
Bt Lintang G10 & $2.99(0.09) \mathrm{e}$ & $3.06(0.21) \mathrm{f}$ \\
Bebar G4 & $2.99(0.28) \mathrm{e}$ & $4.04(0.21) \mathrm{cd}$ \\
Sg. Jernih G3 & $2.31(0.13) \mathrm{f}$ & $3.57(0.18) \mathrm{e}$ \\
Sg. Sokor G9 & $3.11(0.24) \mathrm{de}$ & $4.91(0.26) \mathrm{a}$ \\
Pasir Gajah G2 & $3.47(0.11) \mathrm{c}$ & $5.04(0.08) \mathrm{a}$ \\
\hline
\end{tabular}

${ }^{\dagger}$ Growth rates for respective $G$. boninense isolates on MEA and OPEM were presented in mean of five replications and the numbers in the bracket were standard error.

$\ddagger$ Each medium was analyzed separately. Means within each column of MEA and OPEM medium followed by the same letter are not significantly different at $P=0.05$ after ANOVA-LSD test.

There was no significant difference in mean disease severity index (DSI) among the 14 different treatments at 8 weeks after artificial inoculation (Table 2). The treatments with isolates from Paloh (T3) and Bt. Lintang (T10) started to show significant differences $(P<0.038)$ compared to six other isolates (Fraser/T4, Jeram/T7, Pinji/T8, Pelam/T9, Bebar/T11 and Sg. Sokor/T13) at 12 weeks after inoculation (Table 2). At 16 weeks after planting, Bt Lintang (T10) was not significantly different from treatments with isolates from Paloh (T3), Ulu Pedas (T5), GBA (T6) and Pasir Gajah (T14), but were significantly different $(P<0.03)$ to the other isolates and 2 controls. Variations in the degree of virulence or aggressiveness toward oil palm seedlings and three-leaf stage seedlings for 7 different isolates obtained from three separate estates in Indonesia were also reported by Breton et al., (2006). Information related to variations in virulence of different $G$. boninense isolates from various locations/estates in Malaysia will be useful for future researches in studying Ganoderma pathogens, especially $G$. boninense that responsible for basal stem rot disease in oil palm. Furthermore, slight modifications on the disease classes and approaches for scoring the diseased seedlings were made in current experiment compared to the disease classes or ratings proposed by Nur Ain Izzati and Abdullah (2008) and Sapak et al. (2008). Disease classes incorporated into this study were to address those palms that were without leaf symptoms but fungal mass/basidiocarp was detected approximately $2 \mathrm{~cm}$ from or on the bole and certain isolates that were lesser or least virulence in nature tempted to have fungal mass/fruiting body but no visual symptoms, as well as replicates of a few more virulence isolates observed to cause severe leaf symptoms at the initial stage prior to produce the fruiting bodies.

Linear relationships between disease incidence (DI) and disease severity index (DSI) ranged from 0.913 to 0.977 in terms of $R^{2}$ values (with linear regression in SPSS 1990) over the four separate time points were relatively high. Therefore, either one of the two parameters will be used for future studies. DI and DSI were grouped into four different categories based on the $\mathrm{DI}$ and DSI values: highly virulence - more than $80 \%$; moderately virulence $-50-80 \%$; less virulence $-10-50 \%$; and least virulence $-0-10 \%$. By week $16^{\text {th }}$ after inoculation, Ganoderma boninense isolates from Paloh (T3), Ulu Pedas (T5), GBA (T6), Pelam (T9), Bt Lintang (T10), Bebar (T11), Sg. Jernih (T12) and Pasir Gajah (T14) were grouped under the highly virulence category using DI values as the sole parameter for grouping. Sg. Sokor (T13) was categorized as moderately virulence isolate. However, treatments with Fraser (T4), Jeram (T7) and Pinji (T8) isolates were less virulence (Table 2). Based on the DSI values, four treatments - Paloh (T3), Ulu Pedas (T5), GBA (T6), Pelam(T9) and Pasir Gajah (T14) were categorized under the highly virulence category. Sg. Sokor (T13) was categorized as moderately virulence isolate as well under DSI value. On the other hand, Fraser (T4) treatment was the least virulence pathogenic while Jeram (T7) and Pinji (T8) were classified as less virulence (Table 2).

Variations in the degree of virulence for 12 different $G$. boninense isolates tested in this study ranged from highly virulence to least virulence. Furthermore, there was no correlation between mycelia growth rate (on MEA and OPEM) and degree of virulence (both $\mathrm{DI}$ and DSI) among the $G$. boninense isolates tested (Table 2 and 4 ). This information will be useful for future studies to be carried out for screening BSR tolerance or resistance oil palm progenies, mode of attacks and spread, chemical and biological control for $G$. boninense in oil palms. Variations in the degree of virulence and aggressiveness may cause differences in the results generated from BSR tolerance or resistance progenies and chemical, biocontrol or integrated pest management (IPM) experiments or implications.

High degree of variations in genetic background for $G$. boninense isolates in this study could be due to the isolates was collected from different geographical locations. Genetic variations among different Ganoderma isolates obtained from within same or between palms and within same or different plantations were found to be relatively high with various molecular apporaches, such as mitochondrial DNA restriction fragment length polymorphisms (RFLPs), random amplified polymorphic DNA (RAPD) and Random Amplified Microsatellite (RAMS) (Miller et al., 1999; Latiffah et al., 2005; Rees et al., 2012). Furthermore, heterogeneity in genetic backgrounds among $G$. boninense isolates from infected oil palms was also demonstrated through mating test with monokaryotic cultures and somatic compatibility test (Pilotti et al., 2003; Rees et al., 2012). 


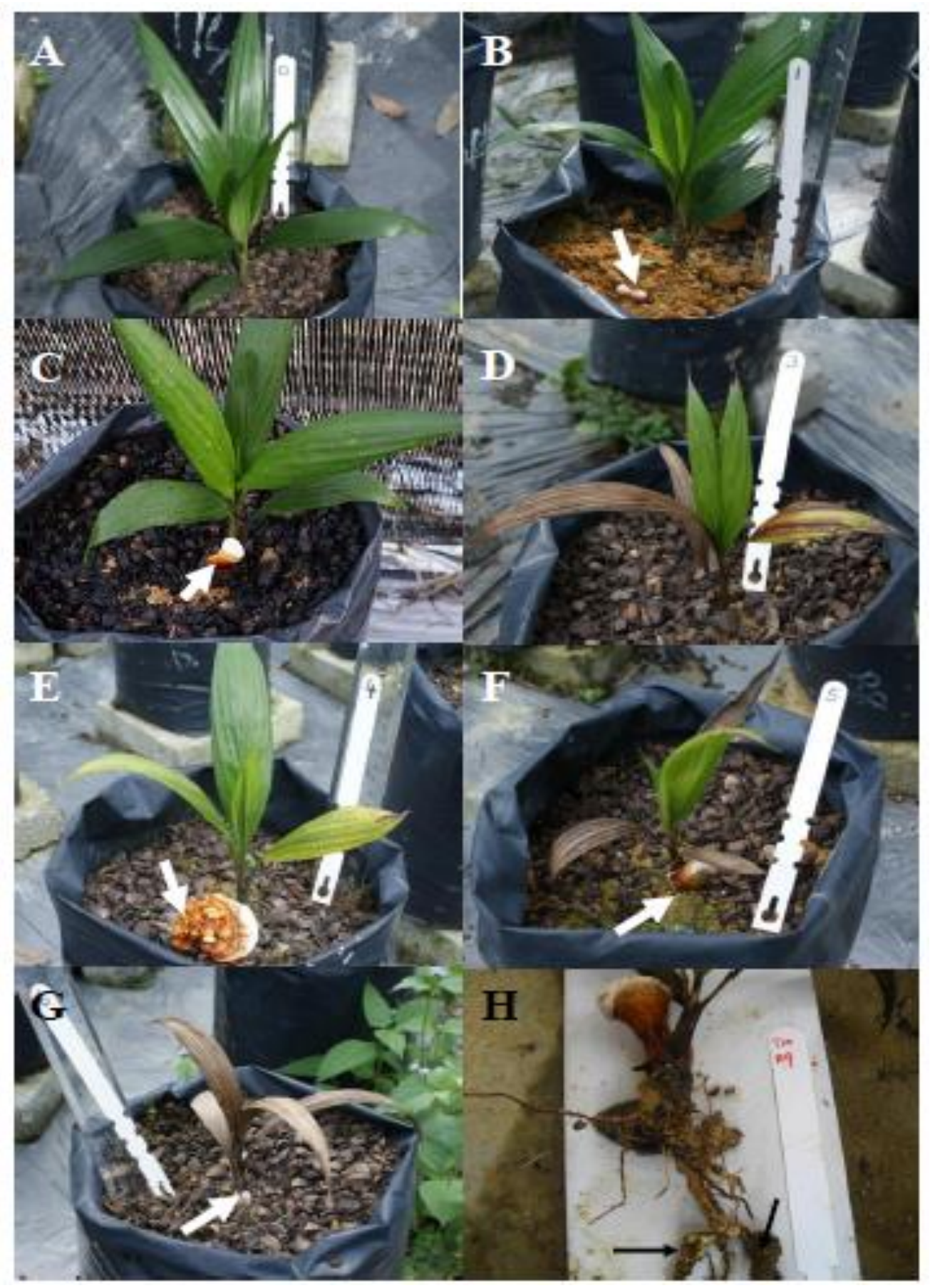

Figure 2: Samples of oil palm seedlings demonstrated different disease classes with arrow pointing at fungal mass or fruiting body: 0 (Healthy plant) (A), 1 (Without leaf symptoms, fungal mass $>2 \mathrm{~cm}$ away from bole) (B), 2 (Without leaf symptoms, fungal mass at bole) (C), 3 (With leaf symptoms, without fungal mass) (D), 4 (With leaf symptoms, fungal mass $>2 \mathrm{~cm}$ away from bole) (E), 5 (With leaf symptoms, fungal mass at bole) (F), and 6 (Dead) (G). Pseudo-sclerotiallike structures formed around the roots $(\mathrm{H})$. 
Campanile et al., (2004) proposed that high degree of genetic variability in the pathogenic fungal isolate may contribute to differences in pathogenic or virulence ability, adaptation of the fungus to new hosts, or improvement in the degree of resistance toward specific plant hosts. Therefore, isolates with different degree of virulence toward oil palm seedlings can be realized.

\section{CONCLUSION}

In conclusion, all twelve Ganoderma isolates tested were confirmed to be Ganoderma boninense through molecular approach and found to show high similarity in term of $18 \mathrm{~S}$ small-subunit rDNA region with $G$. boninense FA-PP28 isolate (obtained from Malaysia - Moncalvo and Buchanan 2008). Sequences obtained from individual $G$. boninense isolates have been deposited in GenBank. In this study, cultures of $12 \mathrm{G}$. boninense isolates were observed to show better growth rate on OPEM under in vitro conditions compared to conventional MEA medium. Therefore, OPEM medium was employed to prepare Ganoderma cultures for artificial rubber wood blocks (RWBs) inoculation. Variations in the degree of virulence in the tested $G$. boninense isolates were reported and illustrated through both the disease incidence (DI) and disease severity index (DSI). All twelve Ganoderma isolates collected from various locations in Malaysia were found to demonstrate different degree of virulence ranging from highly pathogenic to least pathogenic. Furthermore, there were low linear relationships between mycelia growth rate (on MEA and OPEM) and degree of virulence (DI and DSI) among the G. boninense isolates tested. Therefore, it is crucial to incorporate more than one isolate into any researches on screening for Ganoderma resistance or tolerance planting materials, searching for potential biological control agents, and studying bitrophic or tri-trophic interactions, such as pathogen-host or beneficial microbial agent-pathogen-host plant relationships.

\section{ACKNOWLEDGEMENT}

The authors would like to thank the valuable technical assistances of staff from the AAR Crop Protection Lab: Ismail, Amin and Quyyum. We would also like to thank our principles, Boustead Holdings and Kuala Lumpur Kepong Berhad for their permission and financial backing given to the activities that the generated data presented in this article.

\section{REFERENCES}

Ariffin, D., Idris, A.S. and Singh, G. (2000). Status of Ganoderma in oil palm. In: Flood J, Bridge J, Holderness M (eds), Ganoderma diseases of perennial crops. CABI Publishing, Wallingford, UK, pp. 46-68.

Ariffin, D. and Seman, I.A. (1991). A selective medium for isolation of Ganoderma from diseased tissues. In: Proceedings of the 1991 International Palm Oil
Conference, Progress, Prospects and Challenges towards the $21^{\text {st }}$ Century. September 9-14. Malaysian Palm Oil Board, Bangi Selangor, Malaysia, pp 517-519.

Borneman, J. and Hartin, R. J. (2000). PCR Primers that amplify fungal ribosomal RNA genes from environmental samples. Applied and Environmental Microbiology 66, 4356-4360.

Brasier, C.M. and Webber, J.F. (1987). Positive correlations between in-vitro growth rate and pathogenesis in Ophiostoma ulmi. Plant Pathology 36, 462-466.

Brennan, J.M., Fagan, B., van Maanen, A., Cooke, B.M. and Doohan, F.M. (2003). Studies on in vitro growth and pathogenicity of European Fusarium fungi. European Journal of Plant Pathology 109, 577-587.

Breton, F., Hasan, Y., Hariadi, S., Lubis, Z. and de Franqueville, H. (2006). Characterization of parameters for the development of an early screening test for basal stem rot tolerance in oil palm progenies. Journal of Oil Palm Research (Special Issue) 24-36.

Bridge, P.D., O'Grady, E.B., Pilotti, C.A., and Sanderson, F.R. (2000) Development of molecular diagnostic for the detection of Ganoderma isolates pathogenic to oil palm. In: Flood J, Bridge J, Holderness M (eds), Ganoderma diseases of perennial crops. CABI Publishing, Wallingford, UK, pp. 225-234.

Campanile, G., Giove, S.L., and Luisi, N. (2004). Genetic and morphologic variability of Phellinus torulosus isolates in some oak woods of Soutern Italy. Journal of Plant Pathology 86, 105-115.

Campbell, C.L. and Madden, L.V. (1990). Introduction to Plant Disease Epidemiology. John Wiley and Sons, USA.

Cooper, R.M., Flood, J. and Rees, R.W. (2011). Ganoderma boninense in oil palm plantations: Current thinking on epidemiology, resistance and pathology. The Planter 87, 515-526.

Evans, H.C. and Bastos, C.N. (1980). Basidiospore germination as a means of assessing resistance to Crinipellis perniciosa (witches' broom disease) in cocoa cultivars. Transactions of the British Mycological Society 74, 525-536.

Ho, Y.W. and Nawawi, A. (1985). Ganoderma boninense Pat. from basal stem rot of oil palm (Elaeis guinensis) in Peninsular Malaysia. Pertanika 8, 425-428.

Ho, Y.W. and Nawawi, A. (1986a). Germination studies of Ganoderma boninense spores from oil palms in Malaysia. Pertanika 9, 151-154.

Ho, Y.W. and Nawawi, A. (1986b). Isolation, growth and sporophore development of Ganoderma boninense from oil palm in Malaysia. Pertanika 9, 69-73.

Idris, A.S. (1999). Basal stem rot (BSR) of oil palm (Elaeis guineensis Jacq.) in Malaysia. Factors associated with variation in disease severity. $\mathrm{PhD}$ 
Thesis, Wye College, The University of London, UK.

Idris, A., Kushairi, A., Ismail, S. and Ariffin, D. (2004). Selection for partial resistance in oil palm progenies to Ganoderma basal stem rot. Journal of Oil Palm Research 16, 12-18.

Irzykowska, L. and Bocianowski, J. (2008). Genetic variation, pathogenicity and mycelial growth rate differentiation between Gaeumannomyces graminis var. tritici isolates derived from winter and spring wheat. Annals of Applied Biology 152, 369375.

Khairudin, H., Lim, T.K. and Abdul Razak, A.R. (1991). Pathogenicity of Ganoderma boninense pat. on oil palm seedlings. In: Proceedings of the 1991 PORIM International Congress (Agriculture). Kuala Lumpur, Malaysia: Palm Oil Research Institute of Malaysia, 418-423.

Kinge, T.R. and Mih, A.M. (2011). Ganoderma ryvardense $\mathrm{sp}$. No. associated with basal stem rot (BSR) disease of oil palm in Cameroon. Mycosphere 2, 179-188.

Latiffah, Z., Harikrishna, K., Tan, S.G., Faridah, A., and Ho, Y.W. (2005). Random amplified polymorphic DNA (RAPD) and random amplified microsatellite (RAMS) of Ganoderma from infected oil palm and coconut stumps in Malaysia. Asia Pacific Journal of Molecular Biology and Biotechnology 13, 23-34.

Liew K.W. Plant Pathologist and was an Associate Professor in University Sains Malaysia, Minden, Penang, Malaysia and consultant for Advanced Agriecological Research Sdn. Bhd. (AAR). Current address: 90, Lorong Batu Uban Satu, Century Garden, 11700 Gelugor, Pulau Penang, Malaysia.

Lim, T.K., Chung, G.F. and Ko, W.H. (1992). Basal stem rot of oil palm caused by Ganoderma boninense. Plant Pathology Bulletin 1, 147-152.

Miller, R.N.G. (1995). The characterization of Ganoderma populations in oil palm cropping systems. PhD Thesis, University of Reading, UK.

Miller, R.N.G., Holderness, M., Bridge, P.D., Chung, G.F., and Zakaria M.H. (1999). Genetic diversity of Ganoderma in oil palm plantings. Plant Pathology 48, 595-603.

Moncalvo, J.M. and Buchanan P.K. (2008). Molecular evidence for long distance dispersal across the Southern Hemisphere in the Ganoderma applanatum-australe species complex (Basidiomycota). Mycological Research 112, 425436.

Nur Ain Izzati, M.Z. and Abdullah, F. (2008). Disease suppression in Ganoderma-infected oil palm seedlings treated with Trichoderma harzianum. Plant Protection Science 44, 101-107.

Paramananthan, S. (2000). Soils of Malaysia: Their characteristics and identification Vol. 1. Academy of Sciences Malaysia. Malaysia, ISBN: 9839445065.
Paterson, R.R.M. (2007). Ganoderma disease of oil palm - A white rot perspective necessary for integrated control. Crop Protection 26, 1369-1376.

Pilotti, C.A. (2005). Stem rots of oil palm caused by Ganoderma boninense: Pathogen biology and epidemiology. Mycopathologia 159, 129-137.

Pilotti, C.A., Sanderson, F.R., and Aitken, E.A.B. (2003). Genetic structure of a population of Ganoderma boninense on oil palm. Plant Pathology 52, 455-463.

Rees, R.W., Flood, J., Hasan, Y. and Cooper, R.M. (2007). Effects of inoculum potential, shading and soil temperature on root infection of oil palm seedlings by the basal stem rot pathogen Ganoderma boninense. Plant Pathology 56, 862870.

Rees, R.W., Flood, J., Hasan, Y., Potter, U. and Cooper, R.M. (2009). Basal stem rot of oil palm (Elaeis guineensis); mode of root infection and lower stem invasion by Ganoderma boninense. Plant Pathology 58, 982-989.

Rees, R.W., Flood, J., Hasan, Y., Wills, M.A., and Cooper, R.M. (2012). Ganoderma boninense basidiospores in oil palm plantations: evaluation of their possible role in stem rots of Elaeis guineensis. Plant Pathology 61, 567-578.

Robeson, D.J. and Strobel, G.A. (1986). The influence of plant extracts on phytotoxin production and growth rate of Alternaria helianthi. Journal of Phytopathology 117, 265-269.

Sapak, Z., Meon, S. and Ahmad, Z.M.A. (2008). Effect of endophytic bacteria on growth and suppression of Ganoderma infected in oil palm. International Journal of Agriculture \& Biology 10, 127-132.

Sariah, M., Hussin, M.Z., Miller, R.N.G. and Holderness, M. (1994). Pathogenicity of Ganoderma boninense tested by inoculation of oil palm seedlings. Plant Pathology 43, 507-510.

Singh, G. (1991). Ganoderma-the scourge of oil palm in the coastal areas. The Planter 67, 421-444.

SPSS, (1990) SPSS/PC+4.0 Advanced Statistics Manual, Chicago, IL: USA.

Subagio, A. and Foster, H.L. (2003). Implications of Ganoderma disease on loss in stand and yield production of oil palm in North Sumatra. In: Proceedings of the MAPPS Conference August 11, 2003. Kuala Lumpur, Malaysia: Malaysian Plant Protection Society.

Turner, P.D. (1981). Oil palm Diseases and Disorders. Oxford, United Kingdom. Oxford University Press, pp. 280. 